\title{
EDITORIAL
}

\section{Junqian Zhang}

\section{Preface to special issue on nonlinear mechanics of solids}

Received: 9 December 2014 / Accepted: 16 December 2014 / Published online: 13 January 2015

(C) Springer-Verlag Berlin Heidelberg 2015

This special issue of the Archive of Applied Mechanics includes seven papers on mechanics of solids, which are selected from those orally presented at the sixth International Conference on Nonlinear Mechanics (ICNMVI), August, 12-15, 2013, Shanghai, China. The ICNM conference series was initiated in Shanghai in 1985 and traditionally covers a wide range of topical areas on nonlinear mechanics of solids and fluids. The seven papers were rigorously reviewed and subsequently revised by following the normal peer-review procedure of the journal.

The problems investigated in the selected articles include the energy and entropy inflows into a continuum, the wavelet method for solving nonlinear solid mechanics problems, the method for constructing large-scale tensegrity structures, the opto-mechanical behavior of liquid crystal elastomers, the shape transition and stability of helical ribbon, the simulation of structural evolution of silicon nanowires, and the mechanical properties of locally oxidized graphene electrodes.

The guest editor is grateful to the authors for their contributions. I also appreciate the reviewer's constructive comments, which led to improvements in the technical quality and the presentation clarity. Finally, I wish to thank Professor Reinhold Kienzler, the editor of the journal, for inviting me to edit this special issue.

J. Zhang $(\varangle)$

Department of Mechanics, Shanghai University, Shanghai 200444, China

E-mail: jqzhang2@ shu.edu.cn 